[Bull. Agr. Chem. Soc. Japan, Vol. 21, No. 2, p. 86 89, 1957]

\title{
Studies on the Essential Oils of Tobacco Leaves
}

\author{
Part X. Acid Fraction in the Essential Oil of the Japanese \\ Flue Cured Tobacco Leaf Before Redrying and Aging.
}

\author{
By Isao ONIshi and Kyoji Yamasaki \\ Tobacco Reseach Department, Central Research Institule, Japan Monopoly Corporation
}

Received September 19,1956

\begin{abstract}
Acid fraction of the essential oil of Japanese flue cured tobacco leaf, before redrying and aging (BRA), was compared with that of the same leaf after aging (AA) as reported in previous papers ${ }^{1,3}$. The organic acids which were isolated and identified in the essential oil of BRA are similar to those of AA, except that the former contains propionic and methylethylacetic acids, which were not found in the latter. While, on the other hand, total volatile acids in AA was amounted to about three times as much as that of BRA, and cspecially the increase of acetic and phenylacetic acids was remarkable during the process of aging.
\end{abstract}

In the previous papers we have studied the constituents of each fraction in the essential oil obtained from the Japanese flue cured tobacco leaf, after redrying and aging (AA) for in the course of about one year. The same kind of tobacco leaf, having the same grade, stalk position, growing district, before redrying and aging (BRA) was employed in this study in order to investigate changes of the chemical constituents of the essential oil during the process of aging. Besides, we expected to find whether the change of the chemical constituents in the essential oil would suggest the period suitable for the aging of tobacco leaf after it is packed in hogsheads.

From the acid fraction of the essential oil of Japanese flue cured tobacco leaf BRA, the following acids were isolated and identified; formic, acetic, propionic, $\alpha$-crotonic, methylethylacetic, $n$-caproic, $\beta$-methylvaleric, benzoic and phenylacetic acids.

These organic acids from the essential oil of tobacco leaf BRA are similar to those of $\mathrm{AA}$, except in respect of propionic and me-

\footnotetext{
1) I. Onishi and K. Yamasaki, This Bulletin, 19, 137 (1955).
}

2) I. Onishi and K. Yamasaki, This Bulletin, 20, 68 (1956). thylethylacetic acids which were newly isolated from BRA and acetic and phenylacetic acids contents increased during the process of aging.

However, it was noticed that the amount of acidic resinous constituents, which make the isolation and identification of organic acids (i.e., isooctane insoluble fraction) difficult, in the acid fraction of the essential oil BRA was smaller than that of AA. This fact, which was also observed in the case of the carbonyl fraction ${ }^{3)}$, would suggest that the resinous substances increased by polymerization of the dynamic substances, so called by Frankenburg ${ }^{4)}$, during the process of aging.

\section{EXPERIMENTAL}

1) Preparation of Essential Oil: The flue cured tobacco leaves, 1955 crop, harvested in Okayama, before redrying and aging, smoking leaf, special grade, were butted and cut by the same method as usually employed in cigarette manufacturing. As previously reported' ${ }^{1}$, cut tobacco leaf, $135 \mathrm{~kg}$, was steam distilled and the distillate was extracted with ether.

3) I. Onishi and M. Nagasawa, This Bullecin, 21, 43 (1956).

4) W.G. Frankenburg, Advances in Eazymology, 10, 371 (1950). 
TABLE I

Physical and CHEMICAL Constants of the Essential oIl of JaPANESe Flue CuRed TOBACCO LEAF BEFORE REDRYING AND AFTER AGING

$\begin{array}{lcc}\text { Yield (\%) } & 0.133 & 0.215 \\ \mathrm{~d}_{90}^{30} & 0.9840 & 0.829 \\ \mathrm{n}_{\mathrm{D}}^{90} & 1.4798 & 1.4131 \\ \text { Acid value } & 76.81 & - \\ \text { Saponification value } & 119.32 & - \\ \text { Ester value } & 42.51 & -\end{array}$

shows the yield of acid fraction, isooctane soluble and insoluble-fraction, in BRA as compared with: those of AA.

3) Separation of Organic Acids: As reported previously, organic acids were separated by column. chromatography employing silicic acid as an adsorbent and isooctane as an eluting solvent. The chromatograms of low- and high-boiling point fractions are represented in Figs. 1 and 2, respectively.

4) Identification of Organic Acids: Each organic acid isolated by column chromatography was derived.

TABLE II

Compartson of Yield of the ACid Fraction in the Essential OIl of Japanese Flue Cured Tobacco Leaf Before Redrying and After Aging

From the ethereal solution, $179.36 \mathrm{~g}$ of the essential oil of tobacco leaf BRA was obtained (see Table I.) and the characters of its odor were almost the same as that of the essential oil of tobacco leaf AA.

2) Preparation of Acid Fraction: As reported previously, from $179.36 \mathrm{~g}$ of the essential oil BRA, $19.05 \mathrm{~g}$ of the acid fraction which contained a considerable amount of volatile non-acidic compounds (ether, carbonyl compounds etc.) was obtained. In order to remove the volatile non-acidic compounds and collect the low-boiling point fraction, mainly consisting of acetic acid, the acid fraction was fractionally distilled at atmospheric pressure and $2.066 \mathrm{~g}$ of the low-boiling point fraction (b.p. $60-83^{3}$, bath temp. $100-170^{\circ}$ ) was obtained.

The distilling residue was dissolved in ether, and the ethereal solution was extracted with saturated aqueous sodium bicarbonate solution. This aqueous solution was acidified with sulfuric acid, then saturated with sodium chloride and extracted with ether. After removal of ether, $6.918 \mathrm{~g}$ of high-boiling point fraction was obtained. This fraction was extracted two or three times with hot isooctane and $2.047 \mathrm{~g}$ of the isooctane soluble-fraction was obtained. Table II. to its $p$ ubromphenacyl ester and identified by its melting point, infrared spectrum and elementary analysis.

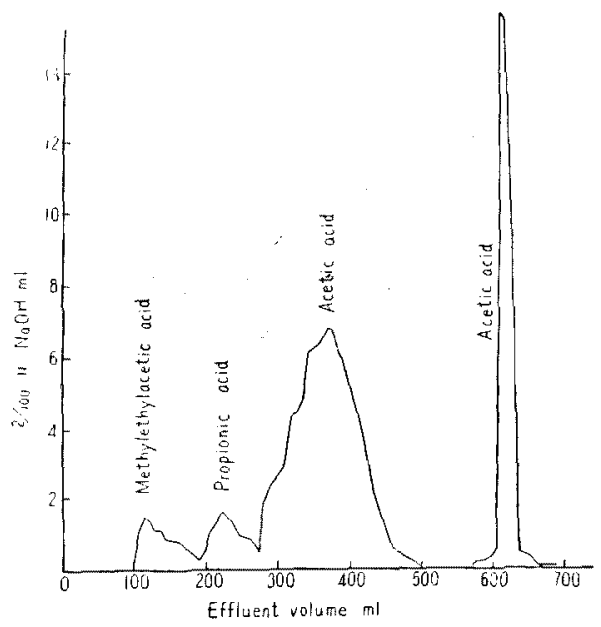

Fig. 1. Chromatographic Separation of Low-boiling Point Fraction.

Developers used were as follows: Isooctane $500 \mathrm{ml}$, Isooctane-Ether $(10 \% \mathrm{v} / \mathrm{v}) 100 \mathrm{ml}$, Ether $200 \mathrm{ml}$.

$13 \mathrm{~g}$. of Silicic acid was used as packing material. 


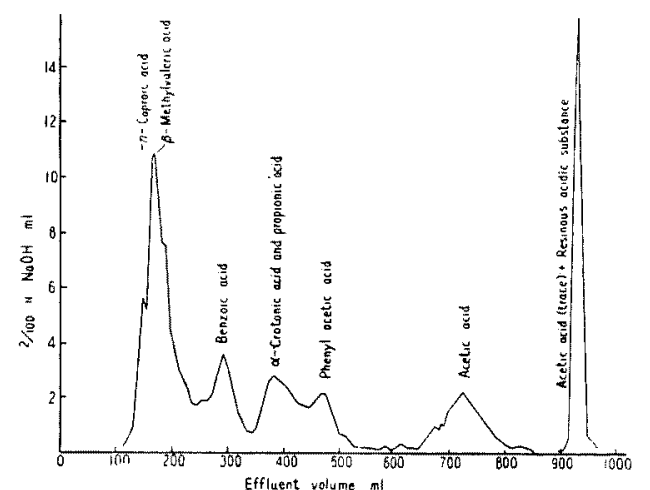

FIG. 2. Chromatographic Separation of High-boiling Point Fraction.

Developers used were as follows: Isooctane $800 \mathrm{ml}$, Isooctane-Ether $(10 \%$ v $/ \mathrm{v}) 100 \mathrm{ml}$, Ether $200 \mathrm{ml}$. with each other.

\section{RESULTS AND DISCUSSION}

Table III. shows the content of each organic acid isolated and identified from the essential oil before redrying and aging, compared with that of after aging. There was no difference in the kind of organic acid between BRA and AA, except that methylethylacetic and propionic acids were newly isolated from BRA.

However, Table II. shows the increase of total volatile organic acid from $141 \mathrm{mg}$ BRA to $474 \mathrm{mg} \mathrm{AA}$, per $1 \mathrm{~kg}$ of tobacco leaf. The content of low-molecular fatty acid, especially acetic acid in the essential oil of

TABLE III

Comparison of THE ACID Fraction IN THE EsSENTIAL OIL OF JAPANESE Flue Cured Tobacco Leaf Before Redrying AND After Aging

\begin{tabular}{|c|c|c|c|c|}
\hline & $\mathrm{Be}$ & drying & & ging \\
\hline & $\underset{\text { leaf }}{\mathrm{mg} / 10 \mathrm{~kg}}$ & $\begin{array}{l}\text { ó for } \\
\text { total acid }\end{array}$ & $\underset{\text { leaf }}{\mathrm{mg} / 10 \mathrm{~kg}}$ & $\begin{array}{l}\% \text { for } \\
\text { total acid }\end{array}$ \\
\hline Formic acid & - & - & trace & - \\
\hline Acetic acid & 98 & 33.9 & 268 & 49.2 \\
\hline Propionic acid & 9 & 2.9 & - & - \\
\hline Isobutyric acid & - & - & 8 & 1.5 \\
\hline$\alpha$-Crotonic acid & 22 & 7.6 & 40 & 7.3 \\
\hline Methylethylacetic acid & 10 & 3.5 & - & $\ldots$ \\
\hline$n$-Caproic acid & 15 & 5.3 & 19 & 3.5 \\
\hline$\beta$-Methylvaleric acid & 82 & 28.3 & 106 & 19.4 \\
\hline Benzoic acid & 32 & 11.2 & 34 & 6.2 \\
\hline Phenylacetic acid & 21 & 7.3 & 70 & 12.9 \\
\hline
\end{tabular}

5) Identification of Methylethylacetic Acid: $p$-Bromphenacyl ester of the acid corresponding to the first peak in Fig. 1 (m.p. 54-5 $5^{\circ}$, showed no depression of melting point upon admixture with $p$-bromphenacyl ester of authentic methylethylacetic acid (m.p. 55-6 ${ }^{\circ}$, and infrared spectra of both derivatives agreed well with each other.

Anal. Found: $\mathrm{C}, 51.88 ; \mathrm{H}, 4.67$. Calcd. for $\mathrm{C}_{13^{-}}$ $\mathrm{H}_{15} \mathrm{BrO}_{3}$ (as the methylethylacetic acid derivative): C, 52.19; H, 5.05 .

6) Identification of Propionic Acid: p-Bromphenacyl ester of the acid corresponding to the second peak in Fig. 1 (m.p. 58-60\%) showed no depression of melting point, upon admixture with $p$-bromphenacyl ester of authentic propionic acid (m.p. 58-9 ) and infrared spectra of both derivatives agreed completely tobacco leaf AA was about 2.5 times as much as that of BRA and an increase of phenylacetic acid by 3 times was observed during the process of aging, but the question of the formation of these acids has not been clarified in detail.

Phenylacetic acid is distributed in many plants, for example, in Japanese peppermint oil, being found as an ester with $\beta, \gamma$-hexenols). In the process of biological degradation of phenylalanine by microorganism 6,7 , phenyl-

5) N. Hirao, "Nihon-Seiyu-Kagaku", Sasaki-tosho Pub. Co., Tokyo, 1939, p. 99.

6) K. Felix, K. Zorn und H. Dirr-Kaltenbach, Z. physiol. Cbem., 247, 141 (1937).

7) T. Uemura, J. Agr. Cbem. Soc. Japan, 13, 1146 (1937). 
acetic acid is produced through phenylpyruvic acid and Polak ${ }^{8}$ reports, that this process would be observed in the biogenesis of phenylacetic acid in plants. Although phenylalanine has been found in the tobacco leaf after fluecuring9), it is not experimentally proved whether phenylacetic acid is produced from the phenylalanine contained in the tobacco leaf.

$\alpha$-Crotonic acid was not generally found in plants except of its presence in Ramalina reticulata10 and animal fat ${ }^{11}$, but it is considered that this acid might be produced from the fatty acid-cycle of Lynen ${ }^{12)}$, which

8) E.H. Polak, Perfum. Ess. Oil Record, 46, 369, 401 (1955); 47, $6(1956)$.

9) S. Ranjan and M.M. Laloraya, Naiure, 177, 235 (1956).

10) J.B.Stark. E.D. Walter and H.S.Owens, J. Am. Chem. Soc*, 72, 1819 (1950).

11) F.L. Brensch and E. Ulysoy, Arch. Biocbem., 11, 489 (1946).

12) F. Lynen, Angetu. Chemt., 67, 463 (1955). plays an important role in the biogenesis of fatty acids.

Acknowledgement. We wish to express our cordial thanks to Prof. Y. Sumiki, Department of Agricultural Chemistry, University of Tokyo, for his wise direction and kind guidance, and also to Director T. Nakashima, Central Research Institute, Japan Monopoly Corporation, for his strong support to us. We are indebted to Dr. M. Matsui, Department of Agricultural Chemistry, University of Tokyo, for the microanalysis and Miss $\mathrm{H}$. $\overline{\mathrm{O}}$ tsuka, $\mathrm{Mr}$. $\mathrm{K}$. Saito for their cooperation in carrying out this experiment. Thank are also due to Mr. J. Kobata, Takamatsu Local Monopoly Bureau, for his cordial cooperation in sampling of tobacco leaf. Last but not least, we are greatly indebted to Emeritus Prof. T. Yabuta for his sound advice. 